\title{
Synthesis of a New Copper-Based Supramolecular Catalyst and Its Catalytic Performance for Biodiesel Production
}

\author{
Fei Chang $D^{1}{ }^{1}$ Chen Yan, ${ }^{2}$ and Quan Zhou ${ }^{3}$ \\ ${ }^{1}$ Institute of Comprehensive Utilization of Plant Resources, Kaili University, Kaili 556011, China \\ ${ }^{2}$ An Shun City People's Hospital, People's Hospital Republic of China, An Shun 561000, China \\ ${ }^{3}$ Pharmaceutical and Bioengineering College, Hunan Chemical Vocational Technology College, Zhuzhou, Hunan 412000, China \\ Correspondence should be addressed to Fei Chang; feichang1980@126.com
}

Received 6 August 2018; Revised 8 October 2018; Accepted 21 October 2018; Published 2 December 2018

Guest Editor: Shunmugavel Saravanamurugan

Copyright (c) 2018 Fei Chang et al. This is an open access article distributed under the Creative Commons Attribution License, which permits unrestricted use, distribution, and reproduction in any medium, provided the original work is properly cited.

A new copper-based supramolecular $(\beta$-cyclodextrins, $\beta$-CD) catalyst was synthesized and used for transesterification of Xanthium sibiricum Patr oil to biodiesel. This catalyst exhibited high activity (88.63\% FAME yield) in transesterification under the ratio of methanol-oil: $40: 1$; catalyst dosage: 8 wt.\%; reaction temperature: $120^{\circ} \mathrm{C}$; and reaction time: $9 \mathrm{~h}$. The XRD, SEM, TEM, XPS, and BET characterization results showed that $\mathrm{Cu}-\beta-\mathrm{CD}$ catalyst was amorphous and had clear mesoporous structure $(17.2 \mathrm{~nm})$ as compared with the native $\beta$-CD. This phenomenon is attributed to the coordination of $\mathrm{Cu}$ and $\beta$-CD.

\section{Introduction}

With the rapid socioeconomic development, the demand for petrochemical energy is on the increase. At the same time, the shortage of energy and environmental pollution have become the focus $[1,2]$. Biodiesel is a good substitute for petrochemical diesel because of its sustainability, biodegradability, and cleanability [3]. Biodiesel, also known as fatty acid monoester, mainly including fatty acid methyl esters (FAME) and fatty acid ethyl esters (FAEE), is typically prepared via esterification or transesterification reactions of animal and vegetable oils with methanol or ethanol in the presence of an acidic and/or basic catalyst [4]. The reaction processes can be divided into homogeneous and heterogeneous ones depending on the type of catalysts, and researchers are more inclined to heterogeneous research for its advantages such as simple steps, easy postprocessing, and less pollution $[5,6]$. Heterogeneous catalysts mainly include inorganic acid salts, solid heteropoly acids, metal oxides $[7,8]$, zeolites [9], and hydrotalcites [10]. Among them, the single and mixed metal oxides were studied by numerous studies due to their environment-friendly, cheap, and efficient catalytic characteristics, which were generally prepared by coprecipitation, sol-gel, impregnation, and hydrothermal methods [11]. In particular, the metal oxides composed of $\mathrm{Ca}, \mathrm{Mg}$, and $\mathrm{Al}$ were extensively illustrated to be active for biodiesel production [12-14]. However, Cu-based catalysts used for efficient biodiesel preparation have been rarely reported so far.

In this report, a new $\mathrm{Cu}$-based supramolecular catalyst was prepared from $\mathrm{CuSO}_{4} \cdot 5 \mathrm{H}_{2} \mathrm{O}$ and $\beta$-CD by simple organic synthesis and was applied to biodiesel synthesis. The results showed that the catalyst had obvious mesoporous structure and good catalytic activity. The results of this study fill the gaps of copper-based catalysts for biodiesel production.

\section{Experiments}

2.1. Materials. Xanthium sibiricum Patr oil was extracted with the reported method [15]. Pure fatty acid methyl esters were purchased from Sigma (USA). $\beta$-CD was purchased from Hongchang Pharmaceutical Reagent Co., Ltd., Xi'an. Anhydrous methanol, $\mathrm{NaOH}$, and $\mathrm{CuSO}_{4} \cdot 5 \mathrm{H}_{2} \mathrm{O}$ are analytically pure (AR) and purchased from Chemical Reagent Co., Ltd., Tianjin. 
2.2. Catalyst Preparation. According to previous reports $[16,17], 2.5 \mathrm{~g} \beta$-CD and $0.8 \mathrm{~g} \mathrm{NaOH}$ were dissolved into $50 \mathrm{~mL}$ distilled water and stirred to completely dissolve at room temperature, and then $50 \mathrm{~mL}$ aqueous solution of $0.5 \mathrm{~g}$ $\mathrm{CuSO}_{4} \cdot 5 \mathrm{H}_{2} \mathrm{O}$ was gradually added at room temperature under magnetic stirring for $1.5 \mathrm{~h}$ and filtered. Upon completion, $500 \mathrm{~mL}$ ethanol was added to the filtrate, and a precipitate formed, which was filtered and washed with absolute ethanol to give a neutral precipitate. The attained solid was further dried at $80^{\circ} \mathrm{C}$ for $5 \mathrm{~h}$.

2.3. Catalyst Characterization. TGA analysis was recorded by NETZSCH STA 429 instrument. XRD patterns were measured with the Bruker D8 advanced X-ray diffractometer (XRD) with $\mathrm{Cu} \mathrm{K} \alpha$ radiation $(\lambda=0.154 \mathrm{~nm})$ at $40 \mathrm{kV}$ and $30 \mathrm{~mA}$ with a step size of 0.02 . The surface morphologies of the catalysts were characterized via FEI inspect F50 type scanning electron microscope (SEM). The internal structure of catalysts was analyzed by the FEI Tecnai G2 F20 S-TWIN $200 \mathrm{kV}$ transmission electron microscope (TEM). XPS analysis was conducted using the Thermo Scientific ESCALAB 250Xi spectrometer employing a monochromatic $\mathrm{Al} \mathrm{K} \alpha \mathrm{X}$-ray source $(\mathrm{h} v=$ $1486.8 \mathrm{eV}$ ) and $500 \mu \mathrm{m}$ test spot area, $15 \mathrm{kv}$ test tube voltage, $10 \mathrm{~mA}$ tube current, and $2 \times 10^{-9} \mathrm{mbar}$ analysis room floor vacuum. The Brunauer-Emmett-Teller (BET) surface areas were measured by $\mathrm{N}_{2}$ adsorption/desorption apparatus (Micromeritics ASAP 2020), and the pore size and pore volume distributions were calculated using the Barrett-Joyner-Halenda (BJH) model.

2.4. Product Analysis. The appropriate amount of $X$. sibiricum Patr oil, catalyst, and methanol were added into a $25 \mathrm{~mL}$ glass three-necked flask with a condensing means and placed in a an oil bath $\left(120^{\circ} \mathrm{C}\right)$ with magnetic stirring for a certain time. After the reaction completion, the reaction mixture was cooled down and filtered, while the excess methanol was removed by rotary evaporation. Hereafter, the FAME contents of the samples were determined by the gas chromatography (GC, Agilent 6890 GC), and the FAME contents were calculated according to the methods reported in [18].

\section{Results and Discussions}

\subsection{Catalyst Characterization}

3.1.1. TGA Analysis. The TGA analysis results of the $\mathrm{Cu}-$ $\beta$-CD catalyst are shown in Figure 1 . It can be seen that the weight loss of the $\mathrm{Cu}-\beta$-CD catalyst mainly included three stages, namely, loss of water $\left(50-150^{\circ} \mathrm{C}\right)$, catalyst decomposition $\left(150-300^{\circ} \mathrm{C}\right)$, and complete decomposition of the catalyst $\left(300-800^{\circ} \mathrm{C}\right)$. Evidently, this catalyst was stable until the temperature of around $150^{\circ} \mathrm{C}$.

3.1.2. $X R D$. Usually, the catalytic activity is closely related to the morphology of the catalyst. The catalytic effect of the amorphous material was generally better than the crystal

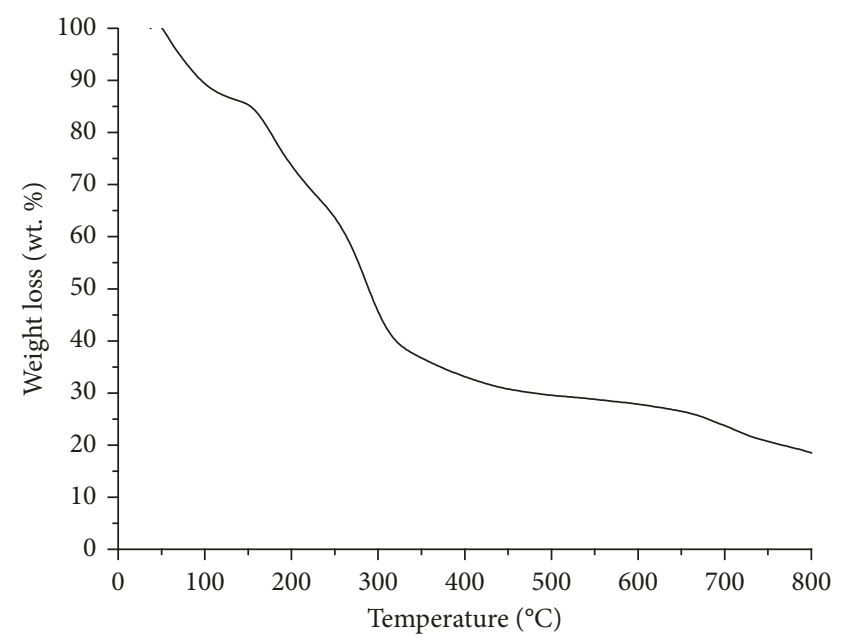

Figure 1: TGA curves of $\mathrm{Cu}-\beta-\mathrm{CD}$ catalyst.

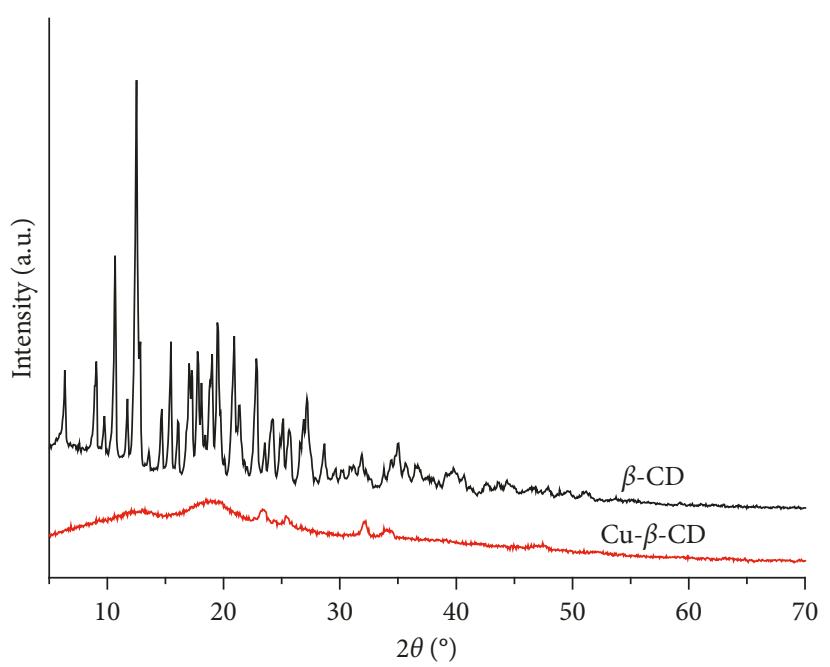

FIgURE 2: XRD patterns of pure $\beta-\mathrm{CD}$ and $\mathrm{Cu}-\beta-\mathrm{CD}$ catalyst.

counterpart $[19,20]$. XRD patterns of $\beta-\mathrm{CD}$ and $\mathrm{Cu}-\beta-\mathrm{CD}$ are shown in Figure 2, it could be clearly seen that the single $\beta$-CD had distinct diffraction peaks, belonging to crystal state material. However, $\mathrm{Cu}-\beta$-CD did not show significant diffraction peaks but appeared as wave packets. So, the structures were greatly changed when the copper ions were involved, which changed its morphology and increased its specific surface area (Figures 3-5), while improving its catalytic activity. This is consistent with the experimental results (Table 1 ).

3.1.3. XPS. The valence of copper ions and structure of the complex were determined by XPS spectra (Figure 6). As can be seen from Figures 6(a) and 6(b), Cu ions existed in the $\mathrm{Cu}-\beta$-CD catalyst. $\mathrm{C} 1 \mathrm{~s}$ might be divided into three signals in Figure 6(a), namely, C-C $(284.7 \mathrm{eV}), \mathrm{C}-\mathrm{O}(286.4 \mathrm{eV})$, and $\mathrm{C}=\mathrm{O}(287.9 \mathrm{eV})$, respectively. In addition, it can be seen from Figure 6(b) that the Cu's basic binding energy was 933.3 ev $(\mathrm{Cu} 2 \mathrm{p} 3 / 2)$ and $953.6 \mathrm{ev}(\mathrm{Cu} 2 \mathrm{p} 1 / 2)$. Therefore, $\mathrm{Cu}^{2+}$, 


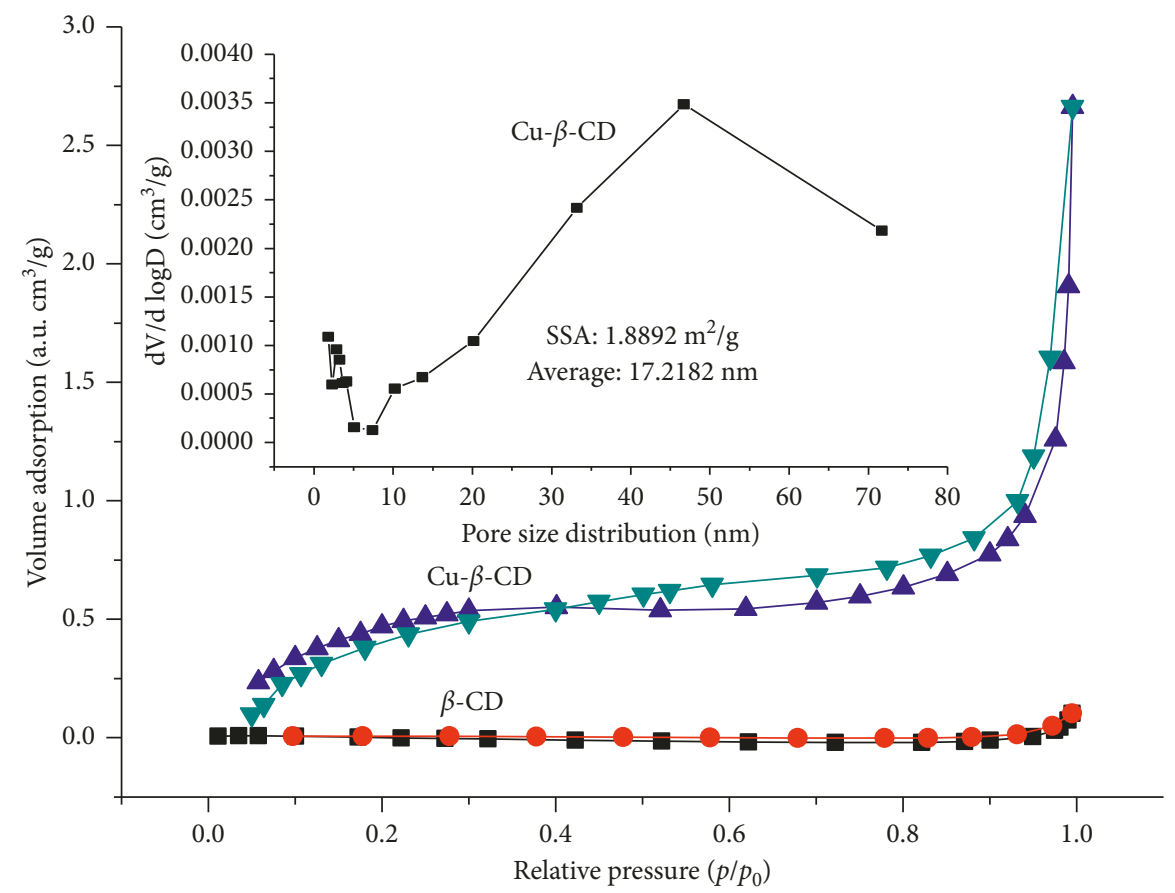

Figure 3: $\mathrm{N}_{2}$ adsorption-desorption isotherms and pore size distribution of $\beta$-CD and $\mathrm{Cu}-\beta-\mathrm{CD}$.
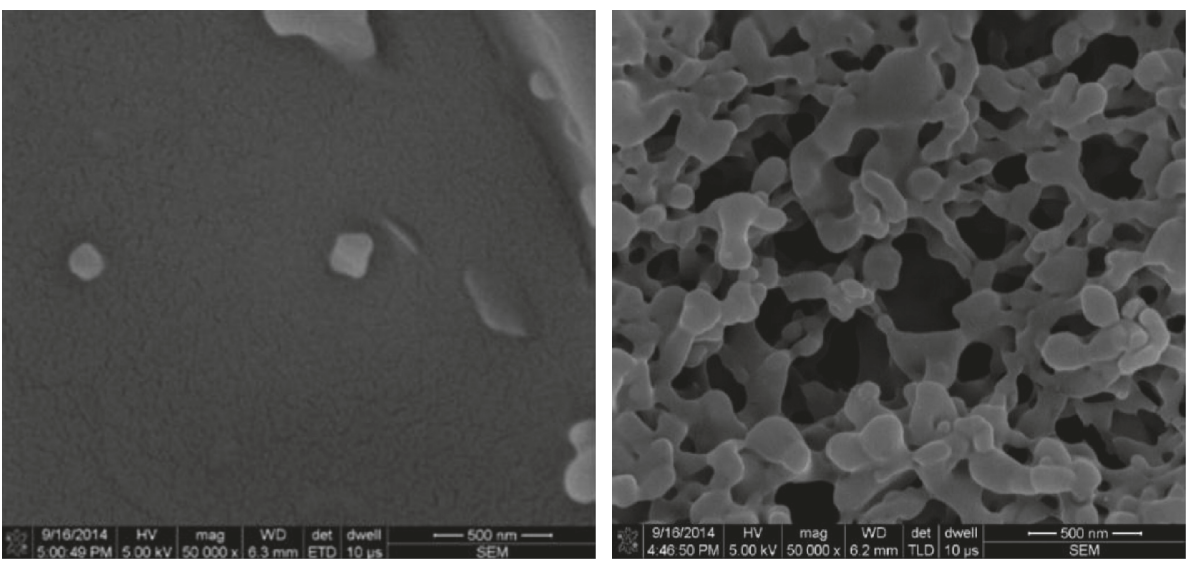

Figure 4: SEM images of pure (a) $\beta$-CD and (b) $\mathrm{Cu}-\beta$-CD catalysts.
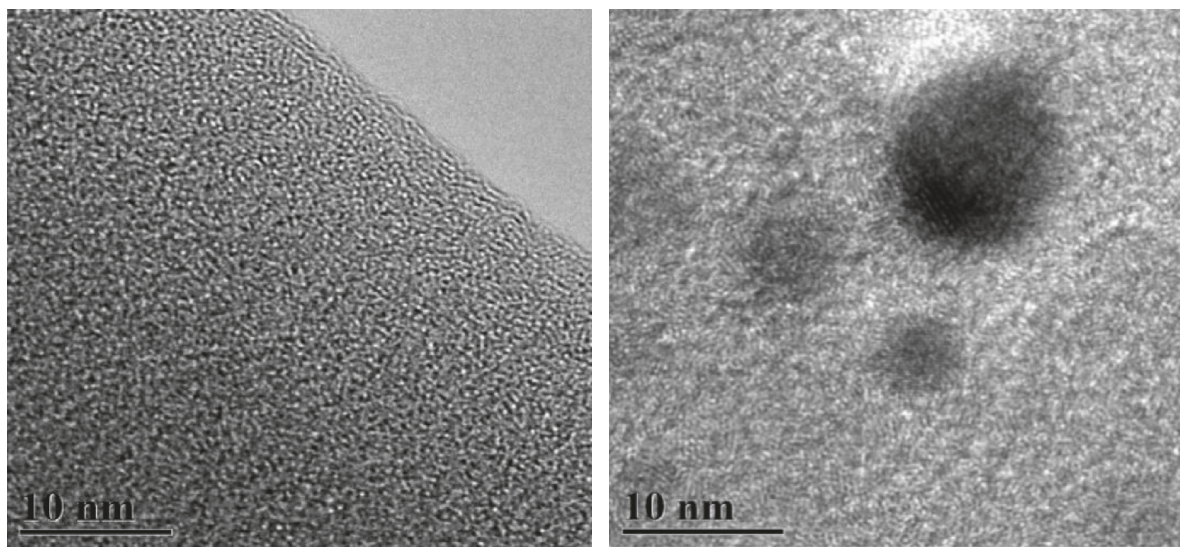

FIGURE 5: TEM images of pure (a) $\beta$-CD and (b) $\mathrm{Cu}-\beta$-CD samples. 
TABLE 1: The catalytic activity of the catalysts.

\begin{tabular}{lcc}
\hline Entry & Catalyst & FAME\% \\
\hline 1 & $\beta-\mathrm{CD}$ (native) & nd \\
2 & $\mathrm{Cu}\left(\mathrm{SO}_{4}\right)_{2} \cdot 5 \mathrm{H}_{2} \mathrm{O}$ & nd \\
3 & $\mathrm{Cu}\left(\mathrm{SO}_{4}\right)_{2} 5 \mathrm{H}_{2} \mathrm{O}+\beta-\mathrm{CD}$ & nd \\
4 & $(\text { simple physical mixture })^{\mathrm{a}}$ & nd \\
5 & $\mathrm{CuO}$ & 88.6 \\
6 & $\mathrm{Cu}-\beta-\mathrm{CD}$ & \\
\hline
\end{tabular}

Condition of reaction: the ratio of methanol-oil: $40: 1$; the amount of catalyst: 8 wt. \%; reaction temperature: $120^{\circ} \mathrm{C}$; reaction time: $9 \mathrm{~h}$; ${ }^{\mathrm{a}}$ physical mixing; nd: not detected; FAME\%: the data of biodiesel production percentages.

copper, is predominantly present in this complex, and coordination compounds were formed such as $\mathrm{CuCO}_{3}$ and $\mathrm{CuO}$. For this study, it can be deduced that a similar $\mathrm{C}-\mathrm{O}-\mathrm{Cu}$ bond existed in the $\mathrm{Cu}-\beta$-CD catalyst. This is consistent with previous reports $[21,22]$ and FT-IR (Figure 1, supporting information (available here).

3.1.4. $\mathrm{N}_{2}$ Adsorption-Desorption Isotherm. The specific surface area (SSA) and pore size are also the main factors that affect the activity of the catalyst. So, SSA and pore size distribution of the $\beta-\mathrm{CD}$ and $\mathrm{Cu}-\beta-\mathrm{CD}$ were studied via $\mathrm{N}_{2}$ adsorption-desorption isotherm and calculated by BET and $\mathrm{BJH}$ methods, respectively. As can be seen from Figure 3, $\beta$-CD did not display apparent hysteresis loops, but hysteresis ring closure point of the $\mathrm{Cu}-\beta-\mathrm{CD}$ appeared at $p / p_{0}=$ 0.4. In addition, the dramatic increase trend in the highpressure section indicated that it belongs to the type IV isotherms and type $\mathrm{H} 4$ hysteresis ring $[22,23]$. These results demonstrated that $\beta$-CD had no distribution of pores and the $\mathrm{Cu}-\beta$-CD possessed slit hole formed by multilayer structure, and its average pore size is $17.2 \mathrm{~nm}$. Those were consistent with SEM and TEM studies. Apart from this, the SSA of Cu- $\beta$-CD catalyst was $1.9 \mathrm{~m}^{2} / \mathrm{g}$, which is much larger than that of $\beta$-CD $\left(0.1 \mathrm{~m}^{2} / \mathrm{g}\right)$ [24].

3.1.5. SEM and TEM. The morphology of the catalyst is typically correlated to its activity directly [25]. In order to understand the structure of $\mathrm{Cu}-\beta-\mathrm{CD}$, the catalyst was characterized by SEM and TEM, and the results are shown in Figures 4 and 5 . The surface of native $\beta-C D$ is smooth (Figure 4), and the obvious pore structure cannot be observed (Figure 5), but the $\mathrm{Cu}-\beta-\mathrm{CD}$ showed multihole structure and heterogeneous mesoporous structure (Figure 4). Furthermore, a uniform worm-like duct structure of the $\mathrm{Cu}$ $\beta$-CD was also observed (Figure 5). So, it can be concluded that the $\mathrm{Cu}-\beta-\mathrm{CD}$ is a porous mesoporous material, and it can be inferred that $\mathrm{Cu}-\beta$-CD catalyst has a larger specific surface area (SSA) than $\beta$-CD, which was confirmed by the BET test results. As we all know, the catalyst with porous mesoporous structures, small particles, and large SSA can improve the activity of the catalyst $[26,27]$, and the $\mathrm{Cu}$ $\beta$-CD should have a high catalytic activity. Accordingly, the results of catalytic performance of the catalysts are shown in Table 1.
3.2. Catalytic Performance of the Catalysts. Catalytic performance of the relevant catalysts is shown in Table 1 (supporting information). As can be seen from Table 1, $\beta$-CD (native), $\mathrm{Cu}\left(\mathrm{SO}_{4}\right)_{2} \cdot 5 \mathrm{H}_{2} \mathrm{O}, \mathrm{Cu}\left(\mathrm{SO}_{4}\right)_{2} \cdot 5 \mathrm{H}_{2} \mathrm{O}+\beta-\mathrm{CD}$ (simple physical mixture), and $\mathrm{CuO}$ did not show catalytic activity (Table 1 , entries $1-5$ ). In contrast, the $\mathrm{Cu}-\beta-\mathrm{CD}$ showed a higher activity (FAME yield: $88.6 \%$, Table 1, entry 6) under 40:1 methanol-oil ratio, $8 \mathrm{wt} . \%$ catalyst load, $120^{\circ} \mathrm{C}$ reaction temperature, and $9 \mathrm{~h}$ reaction time. In combination with the relevant card results that can be determined its catalytic activity, it can be deduced that the superior activity of $\mathrm{Cu}-\beta-\mathrm{CD}$ is mainly due to the $\mathrm{Cu}^{2+}$ and $\beta$-CD which formed the $\mathrm{Cu}-\mathrm{OH}$ bonds, and the $\mathrm{Cu}^{2+}$ may act as electrophilic species to activate ester. Furthermore, the $\mathrm{Cu}-\mathrm{OH}$ bonds act as nucleophilic species to attack the carbon of the ester, and two synergies may weaken the ester bond and make $-\mathrm{OCH}_{3}$ attack ester bonds easily [17].

3.3. Effect of Single Factor on the FAME Content. In order to optimize the biodiesel catalytic process of the $\mathrm{Cu}-\beta-\mathrm{CD}$, reaction temperature, methanol/oil molar ratio, catalyst loading, and reaction time were studied, respectively. The results are shown in Figure 7, and in most chemical reactions, reaction temperature is one of the most important parameters. The choice of temperature has a direct effect on the reaction rate and product yield. As can be seen from Figure $7(\mathrm{a})$, the FAME content is only $20 \%$ at $65^{\circ} \mathrm{C}$, but it increased with the increase of temperature. When the temperature reached $120^{\circ} \mathrm{C}$, the maximum yield is obtained, while continuing to increase the temperature to $140^{\circ} \mathrm{C}$ leads to no change in the FAME. Figure 7 (b) shows the effect of the molar ratio of methanol to oil in the reaction system. When the methanol-oil molar ratio is 10 : $1-50: 1$, it is proportional to the yield of FAME. As the methanol-oil molar ratio is $40: 1$ and $50: 1$, the yield of FAME was $88.39 \%$ and $89.11 \%$, respectively. It can be considered that the increase of the ratio of methanol-oil yields of FAME can be neglected. Taking into account the catalyst concentration and cost, the methanol-oil molar ratio need not be further increased; therefore, the optimal molar ratio of methanol to oil is $40: 1$ in this reaction. Such a high molar ratio of methanol to oil is related to the characteristic of $\beta$-CD having alcoholicity [28]. The catalyst is the most critical factor in transesterification, and Figure 7(c) shows the yield of FAME under 2 wt. $\%-8$ wt. $\%$ catalyst; the content of FAME is lowest with 2 wt.\% catalyst amount, and with the increase of the amount of catalyst, the yield of FAME also increases. The yield of FAME reached its maximum when increasing to $8 \mathrm{wt} . \%$. Therefore, the optimal catalyst loading should be chosen to be $8 \mathrm{wt} . \%$ for the cost problem. The reaction time is also a key factor affecting the reaction result. The impact of reaction time on the yield of FAME is shown in Figure $7(d)$. It can be seen from the Figure $7(d)$ that the conversion rate of FAME reached the maximum after $9 \mathrm{~h}$. This shows that $88.63 \%$ FAME conversion was received under the optimized reaction conditions of 40:1 molar 


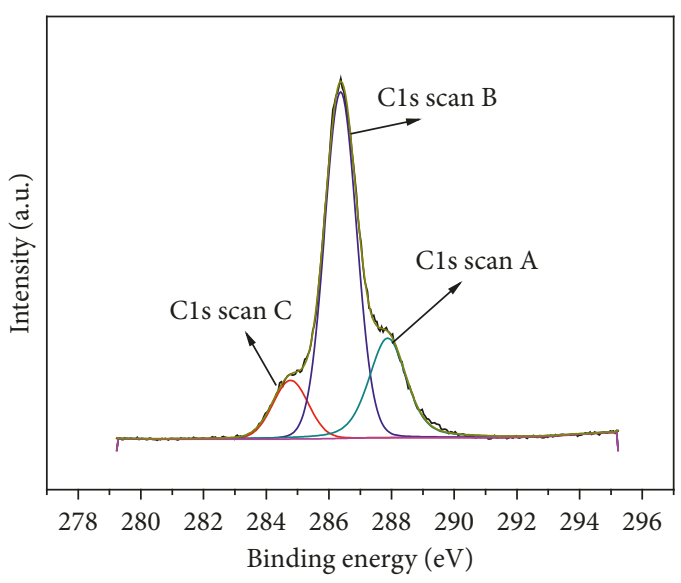

(a)

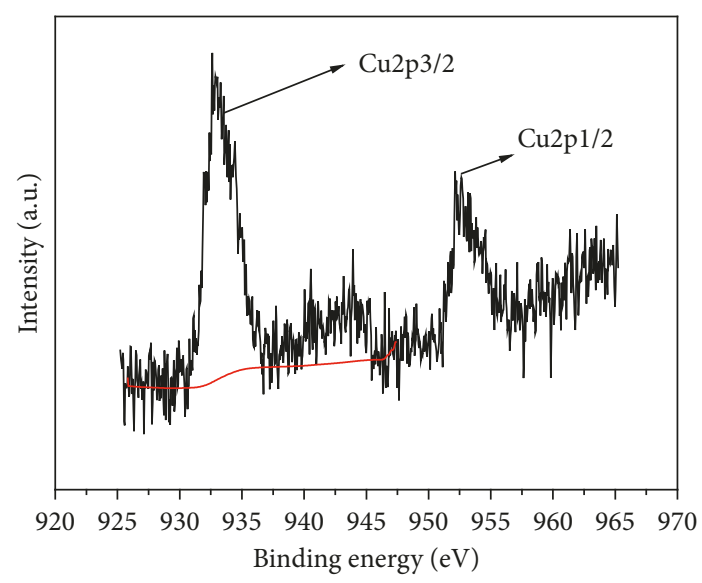

(b)

FIgURE 6: The XPS spectra of $\mathrm{Cu}-\beta-\mathrm{CD}$ catalyst.

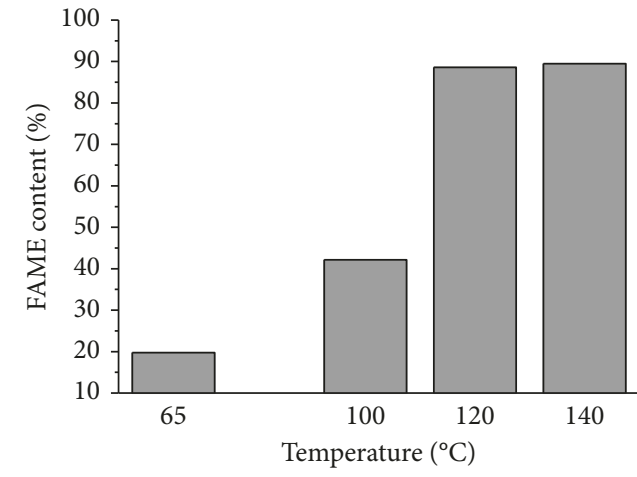

(a)

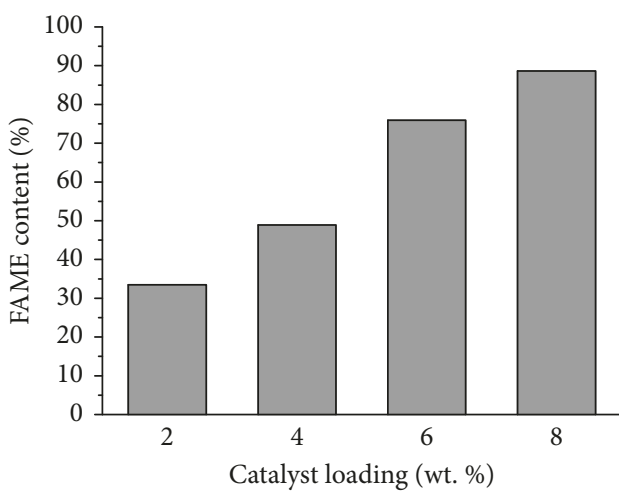

(c)

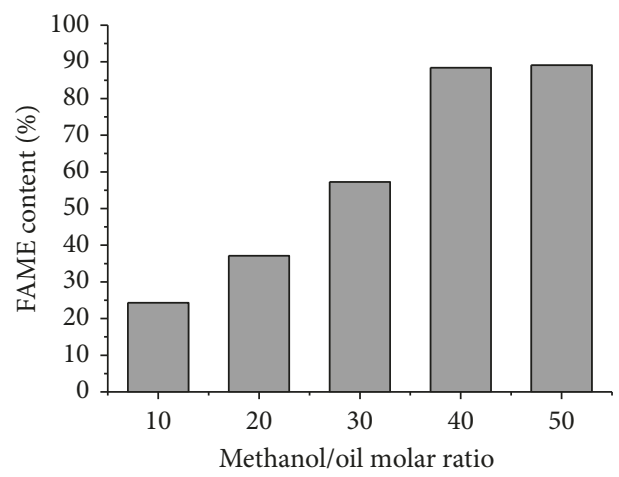

(b)

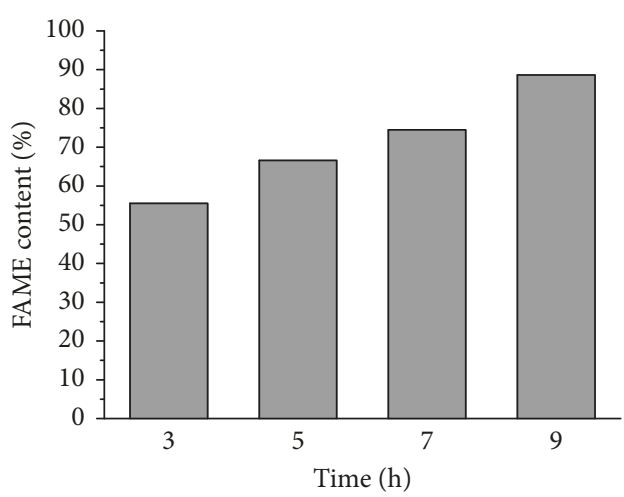

(d)

Figure 7: The effect of single factor on the FAME content. (a) Effect of temperature on FAME content (methanol/oil molar ratio = 40:1, $\mathrm{CA}=8 \mathrm{wt} . \%, t=9 \mathrm{~h}$ ). (b) Effect of methanol/oil molar ratio on FAME content $\left(\mathrm{CA}=8 \mathrm{wt} . \%, T=120^{\circ} \mathrm{C}, t=9 \mathrm{~h}\right)$. (c) Effect of catalyst loading on FAME content (methanol/oil molar ratio $=40: 1, T=120^{\circ} \mathrm{C}, t=9 \mathrm{~h}$ ). (d) Effect of time on FAME content (methanol/oil molar ratio $=40: 1$, $T=120^{\circ} \mathrm{C}, \mathrm{CA}=8$ wt. $\left.\%\right)$.

ratio of methanol/oil, 8 wt. $\% \mathrm{Cu}-\beta-\mathrm{CD}$ amount, $120^{\circ} \mathrm{C}$, and $9 \mathrm{~h}$.

Overall, $\mathrm{Cu}-\beta-\mathrm{CD}$ was stable until around $150^{\circ} \mathrm{C}$, which was a mesoporous material having a large SSA $\left(1.8892 \mathrm{~m}^{2} / \mathrm{g}\right)$ compared with $\beta$-CD $\left(0.11 \mathrm{~m}^{2} / \mathrm{g}\right)$, and its activity lies in the synergy of $\beta$-CD and copper.

\section{Conclusions}

The $\mathrm{Cu}-\beta-\mathrm{CD}$ was prepared by a simple method, which was found to be a kind of uniform worm-like duct and porous mesoporous structured material. It was successfully applied to biodiesel production, giving $88.63 \%$ FAME conversion 
under optimal conditions. This study further demonstrated that $\mathrm{Cu}^{2+}$ and $\beta-\mathrm{CD}$ in the catalyst played a synergistic catalytic role, greatly improving the activity of $\mathrm{Cu}$-based catalyst in transesterification.

\section{Data Availability}

The data used to support the findings of this study are available from the corresponding author upon request.

\section{Disclosure}

Fei Chang and Chen Yan contributed equally to this work.

\section{Conflicts of Interest}

The authors declare that they have no conflicts of interest.

\section{Acknowledgments}

This work was financially supported by Guizhou Provincial State University S\&T Technology Joint Fund Program (nos. LH[2015]7762 and LH [2015]7752).

\section{Supplementary Materials}

FT-IR of $\beta$-CD and $\mathrm{Cu}-\beta-\mathrm{CD}$ is shown in Figure 1 ; it could be seen that peaks of the single $\beta-\mathrm{CD}$ and $\mathrm{Cu}-\beta-\mathrm{CD}$ did not show significant change, and it is obvious that the $\mathrm{Cu}-\beta-\mathrm{CD}$ retains the structure of the $\beta-\mathrm{CD}$. But, there are obvious differences in $800-400 \mathrm{~cm}^{-1}$ and $1600-1200 \mathrm{~cm}^{-1}$; these changes may be caused by the $\mathrm{Cu}-\mathrm{OH}$ of $\mathrm{Cu}$ and cyclodextrin [1-3]. (Supplementary Materials)

\section{References}

[1] Y. He, S. Wang, and K. K. Lai, "Global economic activity and crude oil prices: a cointegration analysis," Energy Economics, vol. 32, no. 4, pp. 868-876, 2010.

[2] S. N. Dodić, S. D. Popov, J. M. Dodić, J. A. Ranković, and Z. Z. Zavargo, "Biomass energy in Vojvodina: market conditions, environment and food security," Renewable and Sustainable Energy Reviews, vol. 14, no. 2, pp. 862-867, 2010.

[3] M. Balat, "Production of bioethanol from lignocellulosic materials via the biochemical pathway: a review," Energy Conversion and Management, vol. 52, no. 2, pp. 858-875, 2011.

[4] A. D. Lele, K. Anand, and K. Narayanaswamy, Surrogates for Biodiesel: Review and Challenges, Springer, Singapore, 2017.

[5] M. R. Avhad and J. M. Marchetti, "A review on recent advancement in catalytic materials for biodiesel production," Renewable and Sustainable Energy Reviews, vol. 50, pp. 696718, 2015.

[6] H. H. Mardhiah, H. C. Ong, H. H. Masjuki, S. Lim, and H. V. Lee, "A review on latest developments and future prospects of heterogeneous catalyst in biodiesel production from non-edible oils," Renewable and Sustainable Energy Reviews, vol. 67, pp. 1225-1236, 2017.

[7] F. Chang, Q. Zhou, H. Pan et al., "Solid mixed-metal-oxide catalysts for biodiesel production: a review," Energy Technology, vol. 2, no. 11, pp. 865-873, 2014.
[8] N. F. Balsamo, K. Sapag, M. I. Oliva, G. A. Pecchi, G. A. Eimer, and M. E. Crivello, "Mixed oxides tuned with alkaline metals to improve glycerolysis for sustainable biodiesel production," Catalysis Today, vol. 279, no. 2, pp. 209-216, 2017.

[9] S. Manadee, O. Sophiphun, N. Osakoo et al., "Identification of potassium phase in catalysts supported on zeolite $\mathrm{NaX}$ and performance in transesterification of Jatropha seed oil," Fuel Processing Technology, vol. 156, pp. 62-67, 2017.

[10] K. G. Georgogianni, A. K. Katsoulidis, P. J. Pomonis, G. Manos, and M. G. Kontominas, "Transesterification of rapeseed oil for the production of biodiesel using homogeneous and heterogeneous catalysis," Fuel Processing Technology, vol. 90, no. 7-8, pp. 1016-1022, 2009.

[11] H. V. Lee, J. C. Juan, T. Y. Yun Hin, and H. C. Ong, "Environment-friendly heterogeneous alkaline-based mixed metal oxide catalysts for biodiesel production," Energies, vol. 9, no. 8, p. 611, 2016.

[12] G. Tao, Z. Hua, Z. Gao, Y. Zhu, Y. Z. Chen, and J. Shi, "KFloaded mesoporous Mg-Fe bi-metal oxides: high performance transesterification catalysts for biodiesel production," Chemical Communications, vol. 49, no. 73, pp. 8006-8008, 2013.

[13] J. R. Mercury, A. H. De Aza, and P. Pena, "Synthesis of $\mathrm{CaAl}_{2} \mathrm{O}_{4}$ from powders: particle size effect," Journal of the European Ceramic Society, vol. 25, no. 14, pp. 3269-3279, 2005.

[14] V. Mandić and S. Kurajica, "The influence of solvents on sol-gel derived calcium aluminate," Materials Science in Semiconductor Processing, vol. 38, pp. 306-313, 2015.

[15] F. Chang, M. A. Hanna, D. J. Zhang et al., "Production of biodiesel from non-edible herbaceous vegetable oil: Xanthium sibiricum Patr," Bioresource Technology, vol. 140, pp. 435-438, 2013.

[16] Y. Matsui, T. Kurita, M. Yagi, T. Okayama, K. Mochida, and Y. Date, "The formation and structure of Copper (II) complexes with cyclodextrins in an alkaline solution," Bulletin of the Chemical Society of Japan, vol. 48, no. 7, pp. 2187-2191, 1975.

[17] F. Chang, Q. Zhou, H. Pan, X. F. Liu, H. Zhang, and S. Yang, "Efficient production of biodiesel from Xanthium sibiricum Patr oil via supramolecular catalysis," Renewable Energy, vol. 111, pp. 556-560, 2017.

[18] H. Pan, X. F. Liu, H. Zhang, K. Yang, S. Huang, and S. Yang, "Multi- $\mathrm{SO}_{3} \mathrm{H}$ functionalized mesoporous polymeric acid catalyst for biodiesel production and fructose-to-biodiesel additive conversion," Renewable Energy, vol. 107, pp. 245252, 2017.

[19] L. M. Correia, R. M. A. Saboya, N. de Sousa Campelo et al., "Characterization of calcium oxide catalysts from natural sources and their application in the transesterification of sunflower oil," Bioresource Technology, vol. 151, pp. 207-213, 2014.

[20] W. Suryaputra, I. Winata, N. Indraswati, and S. Ismadji, "Waste capiz (Amusium cristatum) shell as a new heterogeneous catalyst for biodiesel production," Renewable Energy, vol. 50, pp. 795-799, 2013.

[21] E. Norkus, G. Grincienè, T. Vuorinen, E. Butkus, and R. Vaitkus, "Stability of a dinuclear $\mathrm{Cu}(\mathrm{II})-\beta$-Cyclodextrin complex," Supramolecular Chemistry, vol. 15, no. 6, pp. 425-431, 2003.

[22] E. Norkus, G. Grincienè, T. Vuorinen, and R. Vaitkus, "Cu(II) ion complexation by excess of $\beta$-cyclodextrin in aqueous alkaline solutions," Journal of Inclusion Phenomena, vol. 48, no. 3-4, pp. 147-150, 2004. 
[23] Y. Chen, Y. Cao, Y. Suo, G. P. Zheng, X. X. Guan, and X. C. Zheng, "Mesoporous solid acid catalysts of 12-tungstosilicic acid anchored to SBA-15: characterization and catalytic properties for esterification of oleic acid with methanol," Journal of the Taiwan Institute of Chemical Engineers, vol. 51, pp. 186-192, 2015.

[24] Y. Luo, Z. Mei, N. Liu, H. Wang, C. Han, and S. He, "Synthesis of mesoporous sulfated zirconia nanoparticles with high surface area and their applies for biodiesel production as effective catalysts," Catalysis Today, vol. 298, pp. 99-108, 2017.

[25] Y. H. Taufiq-Yap, H. V. Lee, M. Z. Hussein, and R. Yunus, "Calcium-based mixed oxide catalysts for methanolysis of Jatropha curcas oil to biodiesel," Biomass and Bioenergy, vol. 35, no. 2, pp. 827-834, 2011.

[26] Z. Helwani, M. R. Othman, N. Aziz, W. J. N. Fernando, and J. Kim, "Technologies for production of biodiesel focusing on green catalytic techniques: a review," Fuel Processing Technology, vol. 90, no. 12, pp. 1502-1514, 2009.

[27] D. Y. C. Leung, X. Wu, and M. K. H. Leung, "A review on biodiesel production using catalyzed transesterification," Applied Energy, vol. 87, no. 4, pp. 1083-1095, 2010.

[28] A. Buvari, J. Szejtli, and L. Barcza, "Complexes of short-chain alcohols with $\beta$-cyclodextrin," Journal of Inclusion Phenomena, vol. 1, no. 2, pp. 151-157, 1983. 


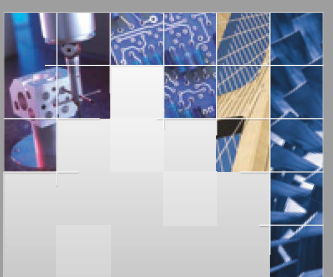

\section{Enfincering}
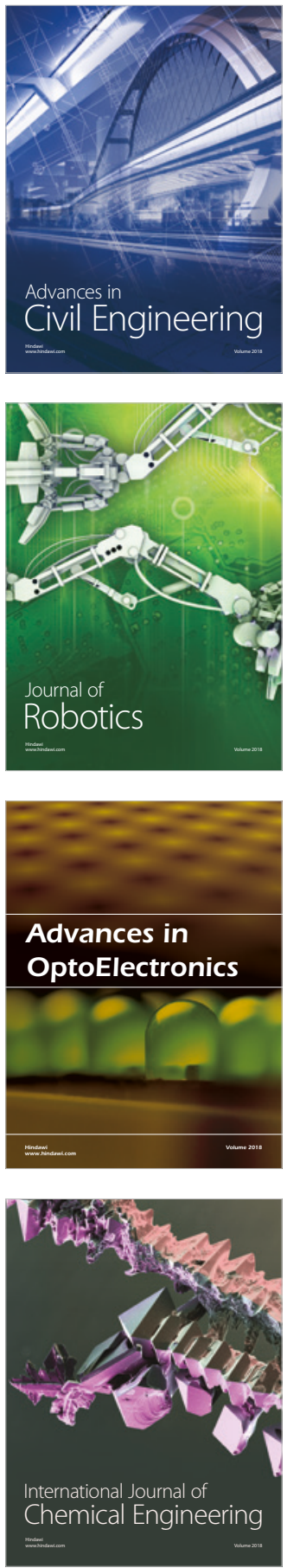

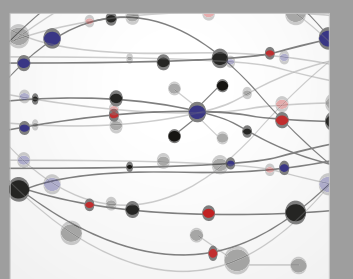

\section{Rotating \\ Machinery}

The Scientific World Journal

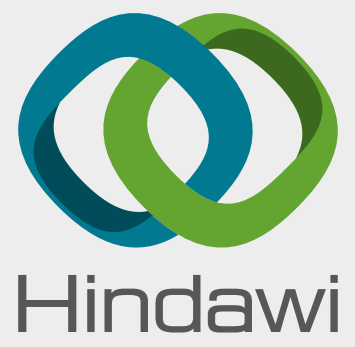

Submit your manuscripts at

www.hindawi.com
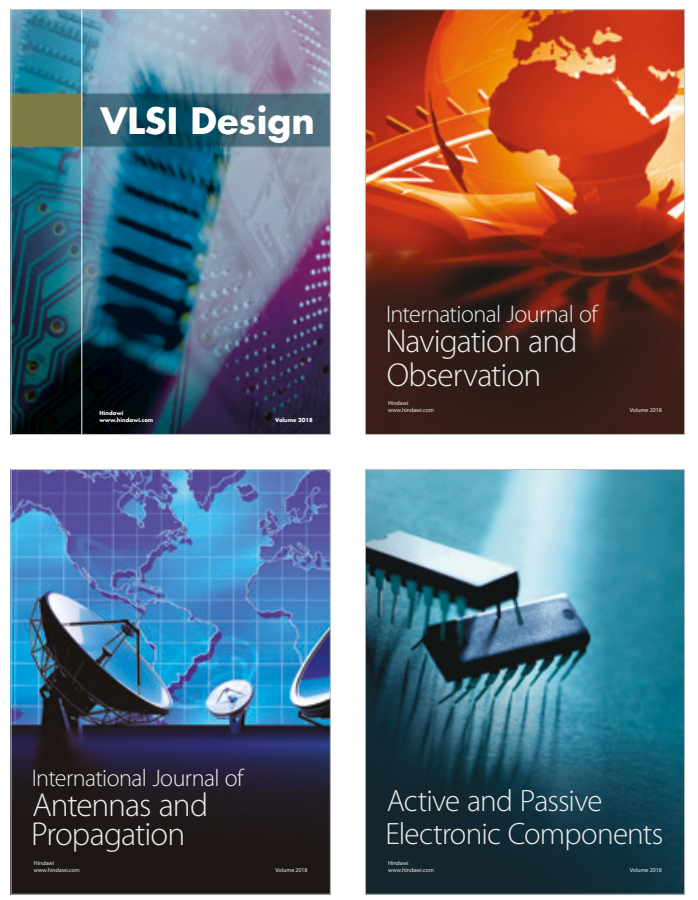
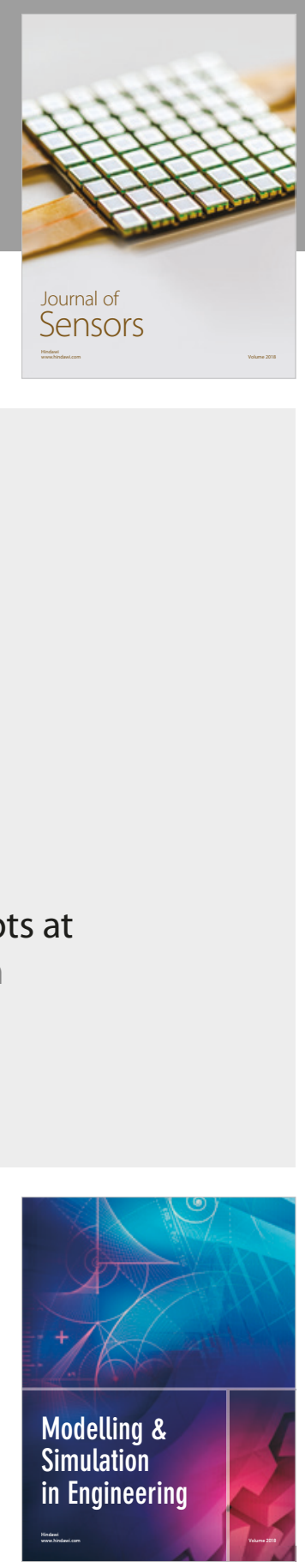

\section{Advances \\ Multimedia}
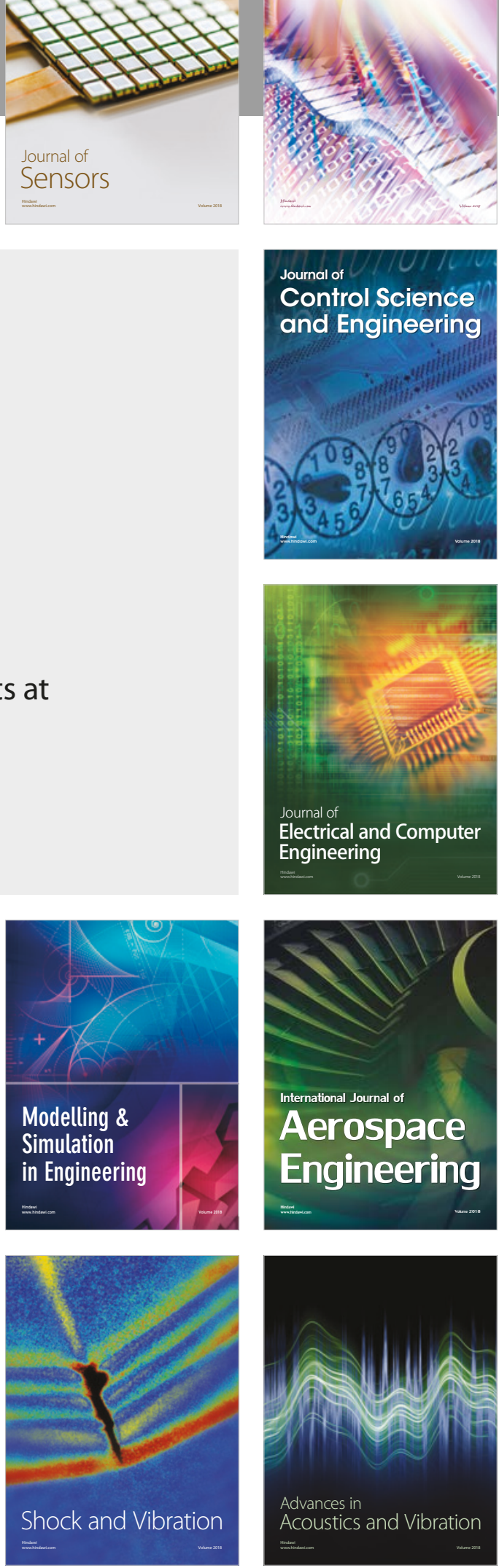